\title{
Mountain Gorillas in Rwanda
}

In a brief note in the September 1969 ORYX, page 9I, Michael Woodford described an encounter with four mountain gorillas on Mt. Karisimba, in the Parc des Volcans in Rwanda. His account was purely concerned with observations made on this one visit to a part of the volcano, but an FPS member in Rwanda, Mr R. I. M. Campbell, writes to point out that it could mislead readers into thinking all was well with the mountain gorillas, apart from a few illegal cattle herds and local people climbing the volcanoes for bamboo; this is not the case. Mr Campbell writes:

'In the Parc des Volcans and the adjoining Parc National Albert, the situation concerning the safety and continued survival of the mountain gorilla-let alone the other animals that still exist there-is extremely critical. In this final retreat the gorillas of the Virunga range of volcanoes are very hard pressed by human intruders and cattle herds. There is virtually no control in these parks. Poachers, cattle herders and honeyhunters roam where they will without restraint. The poachers hunt with bows and arrows, spears and dogs, and set hundreds of bamboo-sprung noose traps to catch the forest antelopes. These men do not hunt quietly and secretly; the dogs have bells fixed round their necks and can be heard for miles, the hunters shout and yell to one another, have no fear of being interrupted, and work the parks from end to end.

'Mr. Woodford says he did not see any evidence of cattle on Mt. Karisimbi. Maybe it was not his intention to convey that cattle are not to be found on Karisimbi, but I am sure readers will infer this. During the height of what might be called the dry season, the slopes of this particular mountain probably support the largest concentrations of cattle. Wherever there is suitable forage, there you will find cattle-throughout the saddle areas and up the sides of the volcanoes, as high as they care to go. Only the steepest slopes and ravines, where they have difficulty in maintaining a secure footing, are relatively safe. The cattle herders live in the mountains for months on end and build small shelters and bomas. They also have no worries about being disturbed.

'A large part of the volcanoes is covered with beautiful hagenia woodland; one seldom finds bamboo growing above the 9,000 foot mark. When the time is right, groups of men invade the parks in search of honey. Wherever possible they smoke the bees out-often leaving the fires smouldering with the result that the tree is burnt out. However, should the bee hive be out of reach they will not hesitate to hack the tree down. What with the bawling of the cattle, the shouts and calls from poachers and herders, the sound of axes and the sight of smoke, the casual observer could be excused for thinking that the volcanoes are freely inhabited-and not park area at all!

'If the Conservateur of the Parc des Volcans would shoot a few of the cattle, the deterrent effect would be great, but I have never heard of an incident where cattle have been killed. There is actually no need to shoot, for cattle can be herded with great ease. They can be impounded or con- 
fiscated with no difficulty at all. What could be easier than destroying trap lines ? But they are left standing. Only the actual capture of men presents any real difficulty, but even they can be chased and disturbed, their shelters destroyed and life made difficult. Throughout the park, only one small area receives some measure of protection. Living at I0,000 ft.under the southern slopes of Mt. Visoke, Miss Dian Fossey, a courageous American girl, who has been studying mountain gorillas for the past three years, does all within her power to keep the intruders at bay, and she puts the Conservateur and his guards to shame. Fearlessly routing herders and poachers alike, destroying hundreds of snares and scores of shelters, confiscating axes, spears, bows and arrows and anything else left by the men in their hurry to get away, she ensures that the gorillas in her study area are able to live in relative peace and security-but her range is small, and what of the gorilla groups that survive in other sections ? In all probability the four animals seen by $\mathrm{Mr}$ Woodford are some of the remnants of a group, or groups, hunted and scattered when park guards captured two youngsters for a Zoo in Germany.* The captures took place early in 1969, and who knows how many animals were hurt and killed when the operation was carried out ?

What of the future of mountain gorilla ? Obviously, if present conditions continue and become worse, they have no long-term future. The old boundaries of the Parc des Volcans have long since been passed by settlement schemes, and further settlements are planned. Control over the area is so slight there may as well be none. The few gorilla groups that survive are increasingly confined to the final and steepest slopes of the volcanoes, and even there they are not free from disturbance. The slow process of extinction is well on its way.

Note: Another serious threat to the gorillas, we learn from another member recently returned from Rwanda, is the decision to excise 10,000 hectares from the national park in order to grow pyrethrum. Settlers have been brought in, roads built, and the wildlife in the area destroyed.-Editor

\section{Malawi's New Game Warden}

In Malawi Major Bruce Kinloch has been appointed Chief Game Warden, and the staff strengthened by the appointment of a biologist. The Beit Trust has given $£ 4550$ for three boreholes and pumps in the Lengwe Game Reserve, which will allow supplies to be maintained in the dry weather of July and August.

\section{White Rhinos for Mozambique}

The South African Wildlife Foundation has given R5000 for the removal of 56 white rhinos from the Umfolosi Game Park in Natal to Gorongosa National Park and Maputo Game Reserve in Mozambique.

\section{Oil at Sea}

The representatives of 34 nations attending the IMCO (International Maritime Consultative Organisation) in London last October agreed on more stringent rules for controlling the discharge of oil at sea: the discharge of tank washings with more than Ioo parts oil per million of water is forbidden in all sea areas; also forbidden is the discharge of oil residues within 50 miles of any shore.

- See Oryx December 1969 page 143 